South African Journal of Geomatics, Vol. 6. No. 3, October 2017

\title{
Precipitable Water Comparisons Over Ghana using PPP Techniques and Reanalysis Data
}

\author{
${ }^{1}$ Acheampong, A. A., ${ }^{1}$ Fosu, C., ${ }^{1}$ Amekudzi, L. K., ${ }^{2}$ Kaas, E. \\ ${ }^{1}$ Kwame Nkrumah University of Science and Technology, Kumasi, Ghana \\ ${ }^{2}$ Niels Bohr Institute, Københavns Universitet, Denmark
}

DOI: http://dx.doi.org/10.4314/sajg.v6i3.13

\begin{abstract}
Atmospheric Water vapor is an important greenhouse gas and contributes greatly in maintaining the Earth's energy balance. This critical meteorological parameter is not being sensed by any of the 22 synoptic weather stations in Ghana. This study presents a highly precise tool for water vapor sensing based on the concept Global Navigation Satellite Systems (GNSS) meteorology and tests the computed results against global reanalysis data. Conventional approaches used to sense the atmospheric water vapor or Precipitable Water $(P W)$ such as radiosondes, hygrometers, microwave radiometers or sun photometers are expensive and have coverage and temporal limitations. Whereas GNSS meteorological concept offers an easier, inexpensive and all-weather technique to retrieve PW or Integrated Water Vapor (IWV) from zenith tropospheric delays (ZTD) over a reference station. This study employed precise point positioning (PPP) techniques to quantify the extend of delays on the signal due to the troposphere and stratosphere where atmospheric water vapor resides. Stringent processing criteria were set using an elevation cut-off of 5 degrees, precise orbital and clock products were used as well as nominal tropospheric corrections and mapping functions implemented. The delays which are originally slanted are mapped unto the zenith direction and integrated with surface meteorological parameters to retrieve PW or IWV. The gLAB software, Canadian Spatial Reference System (CSRS) and Automatic Precise Positioning Service (APPS) online PPP services were the approaches used to compute ZTD. PW values obtained were compared with Japanese Metro Agency Reanalysis (JRA), European Centre for Medium-Range Weather Forecasts Reanalysis (ERA-interim) and National Center for Environmental Prediction (NCEP) global reanalysis data. Correlation analysis were run on the logged station data using the three approaches and global reanalysis data. The obtained results show stronger correlation between the retrieved PW values and those provided by the ERA-interim. Finally, the study results indicate that with a more densified network of GNSS base stations the retrieved PW or IWV will greatly improve numerical weather predictions in Ghana.
\end{abstract}

Keywords: GNSS Signals, PPP, Integrated Water vapour, Precipitable Water, Reanalysis Models 


\section{Introduction}

As a major constituent in the atmospheric greenhouse gases, water vapour concentration is not significantly influenced by direct anthropogenic activities (USGS-Editors, 2011; Seidel, 2002). This is because water vapour contributes to weather phenomena through natural evolution and feedback mechanism. Again its contents in the atmosphere is highly variable both in space and in time due to temperature changes, atmospheric circulation and micro- physical processes (Pottiaux, 2010; Zebker et al., 1997; Rocken et al., 1993). According to Solomon et al. (2007), an estimated 70\% of the recent rises in atmospheric temperature are attributed to water vapour feedback. Additionally, the long-term surface warming under an assumed doubling of the atmospheric carbon dioxide are as a result of enhanced radiation dependent cloud and water vapour feedbacks (IPCC, 2014).

The amount and distribution of water vapour in space (horizontal and vertical) is a major parameter in the development of Numerical Weather Prediction (NWP) models and its importance cannot be underestimated. Sensing and measurement of water vapour by conventional methods such as radiosondes, hygrometers, microwave radiometers, sun photometers are affected by meteorological conditions (Maghrabi and Al Dajani, 2013; Pérez-Ramírez et al., 2012; England et al., 1992). In addition, they are expensive and have coverage limitations. Again water vapour is under sampled in current operational meteorological and climate observing systems (Pichelli et al., 2010; Pierdicca et al., 2009; Gendt et al., 2003). The timely delivery and availability of fine-resolution and accurate 3D water vapour field measurements would lead to substantial improvements in NWP model initialization (Andersson, 2014; Sahoo et al., 2013). The Ghana Meteorological Agency (GMet), the institute responsible for weather forecasting has 22 synoptic stations but unfortunately none is equipped to sense atmospheric water vapour. GMet instead uses most products from the European Center for Medium-Range Weather Forecasts (ECMWF) and other global numerical weather prediction models for their activities. These NWP server products are very good but there still exhibits substantial data gaps with respect to ground-based GNSS observational networks for the African region (refer Figure 1). Seidel et al., 2009 and Teunissen, 2003 have reported of densification of stations of the Global Climate Observing System (GCOS) Upper-Air Network (GUAN) with greater availability and improved data accessed for weather forecasting. With these modernization efforts being carried-out, are aimed at improving coverage and data availability which will go a long way to improve and enhance global weather forecasting. 


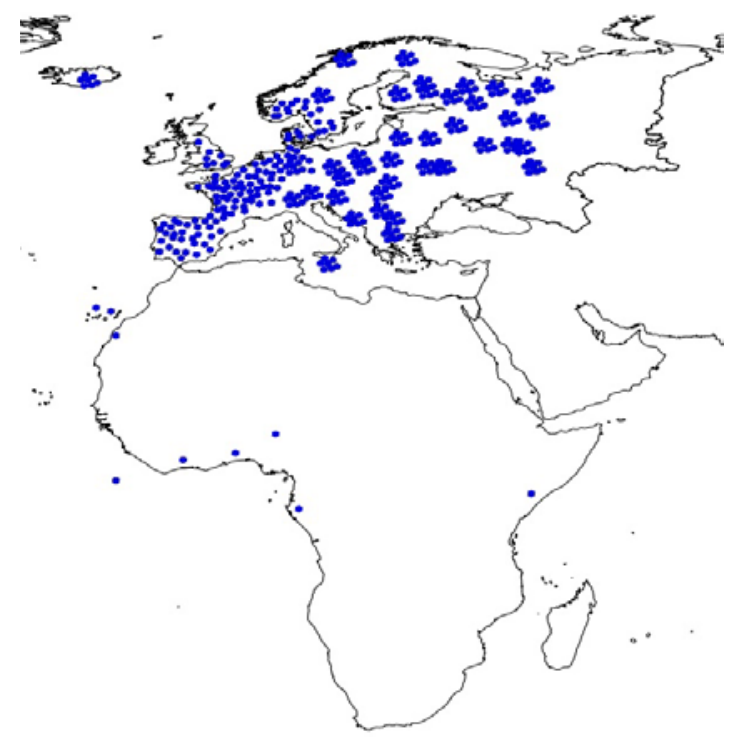

Figure 1: Locations of Ground-Based GPS Stations (shown in blue dots) used by ECMWF

This paper utilizes the concepts of GNSS Meteorology to characterized atmospheric water vapour for use in Numerical Weather Prediction (NWP) modelling, downscaling and model verification. The concept was proposed over two decades ago by Bevis et al. (1992) and patented by Solheim and Ware (1997). This GNSS technique estimates the propagation delays on the signals caused by the neutral atmosphere and the magnitude of the delayed component is directly proportional to the atmospheric water vapour. Tropospheric delays are estimated using either double differencing based on Differential GNSS (DGNSS) for a network of stations or Precise Point Positioning (PPP) for single stations. PPP approach was used for the study because data from a single base station were processed. GNSS Meteorological method is highly accurate irrespective of adverse meteorological conditions, inexpensive and with modelling capabilities to estimate errors with high temporal and spatial resolutions. There is an added advantage that retrieved precipitable water or integrated water vapour can be directly assimilated into NWP models (Bennitt and Jupp, 2012; Bengtsson et al., 2003; van der Marel et al., 2003; Johnsen and Kidder, 2002).

\section{Methods and Data}

To ascertain the accuracies and precision of estimates provided by the Precise Point Positioning techniques for the computation of zenith tropospheric delays, three (3) different approaches were used. An open-source GNSS processing software called gLAB (Hernandez-Pajares et al., 2010) and two online PPP services namely Automatic Precise Positioning Service (APPS) (APPS, 2015; Lichten et al., 2005) and Canadian Spatial Reference System Precise Point Positioning (CSRS-PPP) (CSRS, 2015; Mireault et al., 2008; T'etreault et al., 2005). PPP processing technique was used because datasets for the study came from a single station in Kumasi, Ghana. PPP implementation is based on carrier phases (Kouba and H'eroux, 2001). The knowledge of the precise coordinates of the reference receiver, inter-station distance limitation and simultaneous observations as required in doubledifferenced differential techniques are not needed. These facts make PPP techniques more 
advantageous for single-station GNSS Meteor assignments. Following Misra and Enge (2011), the GNSS carrier phase observable equation is given as:

$$
\emptyset=\lambda^{-1}\left[R+I_{\phi}+T_{\phi}\right]+\frac{c}{\lambda}\left[\delta t_{r}-\delta t^{s}\right]+N+\varepsilon_{\rho}
$$

where $R$ is the true range, $I_{\phi}$ and $T_{\phi}$ are the delays associated with signal transmission through the ionosphere and troposphere delays, $\varepsilon_{\rho}$ are measurement noise, $c$ is speed of light in vacuum, $\left(\delta t_{r}-\delta t^{S}\right)$ are receiver and satellite clock biases respectively. $\phi$, is carrier phase, $\lambda$ is wavelength, $N$ is integer ambiguity. However, the PPP dual-frequency functional model for carrier phases, $\Phi^{s}$, from satellite, $s$, to receiver, $r$, as given by Subriana et al. (2013) is:

$$
\begin{gathered}
\Phi_{r}^{S}=\rho+c \Delta t_{r}-c \Delta t^{S}+I_{\phi}+T_{\phi}+\Delta \rho_{r e l}+\Delta d_{m p}+c \alpha_{r}+c \alpha^{s}+\Delta d_{p c v}+\lambda\left(\omega+\alpha_{r}+\alpha^{s}+N\right) \\
+\varepsilon_{\Phi}
\end{gathered}
$$

The true range, $\rho$, can hardly be obtained as its adulterated with offsets caused by satellite and receiver clocks, $c \Delta t_{r}$ and $c \Delta t^{s}$, ionospheric and tropospheric delays, $\alpha_{r}$ and $\alpha^{s}$ are phase biases for receiver and satellite, $\Delta \rho_{\text {rel }}$ is range correction due to relativistic effects, $\omega$ is a phase wind-up correction, $\lambda$ is wavelength, $N$ is ambiguity for the carrier frequency. $\Delta d_{p c v}$ is frequency dependent delay due to the phase center variations, $\Delta d_{m p}$ is delay due to multipath, $\varepsilon_{\rho}$ and $\varepsilon_{\Phi}$ are the remaining un-modelled errors in the measurements. Accounting for all these errors in Equation 2 as shown in Subriana et al. (2013) the estimated slant tropospheric delays are mapped unto the zenith. The Zenith Total Delays (ZTD) which is obtained after mapping all slant delays are made up of two components: the zenith hydrostatic delays (ZHD) for the dry part and zenith wet delays (ZWD) for moist delays. Integrated Water Vapour (IWV) and Precipitable Water (PW) can then be retrieved from the computed ZWD values using surface meteorological parameters, formulas and methodologies defined in Schu“ler (2006); Bevis et al. (1994); Elgered et al. (1991); Askne and Nordius (1987). Integrated Water Vapour (IWV) in units of $\mathrm{kg} / \mathrm{m}^{2}$ refers to the quantity of the atmospheric water vapour over a specific location and Precipitable Water (PW) is used to express the height of an equivalent column of liquid water in units of length. Bevis et al. (1992) gives IWV as:

$$
I W V=\int_{0}^{\infty} p_{v}(h) d h==\frac{1}{R_{w}} \int_{0}^{\infty} \frac{e(h)}{T(h)} d h
$$

where $p_{v}$ is the partial density of water vapour in $\mathrm{kg} / \mathrm{m}^{3}$; $e$ is water vapour pressure; $T$ is temperature in kelvin; the height $h$ in metres and $R_{w}$ is the specific gas constant for water vapour in $J /(\mathrm{kgK})$. PW relates to IWV by diving with the density of liquid water, $\rho_{w} . P W=I W V / \rho_{w}$. Again IWV is related to the ZWD using a dimensionless quantity as conversion factor, $\Pi$ :

$$
I W V=\frac{Z W D}{\Pi}, \quad P W=\frac{Z W D}{\rho_{w} \cdot \Pi}
$$

Introducing a mean temperature, $T_{m}$, which is defined as: $T_{m}=0.72 T_{s}+70.2$, where $T_{s}$ is the surface temperature. The conversion factor finally becomes:

$$
\Pi=10^{-6} \rho_{w} R_{w}\left(k_{2}^{\prime}+\frac{k_{3}}{T_{m}}\right)
$$


The dimensionless constant computed using Equation 5 ranged between 0.1598 to 0.1665 , with an average value of 0.1629 and a standard deviation of 0.0013 . The average value of 0.1629 was used for PW computations in the study. Bevis et al. (1994) computed the dimensionless constant to be approximately 0.15 , and they found $\Pi$ to be a function of season and location. The computed $\Pi$ for this study falls within the $20 \%$ recommended range variation identified by Liou et al. (2001) and Bevis et al. (1994).

In this study, GPS data was collected from a Base Station on the campus of Kwame Nkrumah Univ. of Science \& Tech (KNUST), Kumasi. This station has been running since February 2013 and uses a 12-channel Sokkia GSR-2600 dual-frequency receiver. Data spanning the months of September 2014 - December 2014 were used. Data were split into 24hourly datasets, pre-processed and quality-controlled with TEQC (Estey and Meertens, 1999). Meteorological data was obtained from a Portable Automatic Weather Stations (AWS) built by Sutron Corporation ${ }^{\circledR}$, USA for the Energy Center, KNUST. In addition to the GPS datasets, PW or total column water vapour were downloaded from three global reanalysis model servers. The reanalysis data used were from the National Center for Environmental Prediction (NCEP) (Dattore et al., 2015; Kistler et al., 2001), Japanese Metro Agency Reanalysis (JRA) (Ebita et al., 2011) and ERA-Interim from the European Centre for Medium-Range Weather Forecasts (Dee et al., 2011). The downloaded data were in the netCDF formats and climate data operators (CDO) software (Schulzweida et al., 2009) was used for data manipulation and extraction for further processing and analysis.

\section{Data Processing}

An a priori or possibly the precise knowledge of the Base station's antenna position must be known in a specific reference datum before data can be processed using PPP techniques. For this study the ITRF2008 reference frame was used (Altamimi et al., 2011). The precise coordinates of the antenna position were determined by comparing GNSS Baseline Differential processing with data submitted to APPS and CSRS-PPP online servers. The final result was fed into the gLAB for ZTD estimations. The criteria set in gLAB were an elevation mask of $5^{\circ}$, modified Niell mapping functions for mapping slant delays unto the zenith and L1-C1 differences for cycle-slip detections. The rest are data decimation of 300secs, Klobuchar model for ionospheric correction (Klobuchar, 1996) and corrections for relativistic, antenna phase centres and ocean tidal loading effects (Subriana et al., 2013).

Processing with the online servers were done by first registering with the services and formatting data to meet the input requirements. Data were subsequently uploaded via the web. Output results were downloaded in a compressed format and extracted then files containing ZTD were identified. Using the GREP command in UNIX, ZTDs at hourly time-marks were extracted from the output reports. Some key features of the online services used are given in Table 1. 
South African Journal of Geomatics, Vol. 6. No. 3, October 2017

Table 1: Online PPP service comparisons

\begin{tabular}{|c|c|c|}
\hline & \multicolumn{2}{|l|}{ Online Processing Service } \\
\hline & CSRS-PPP & APPS \\
\hline Registration & Mandatory & $\begin{array}{l}\text { Needed if you want to alter processing } \\
\text { parameters }\end{array}$ \\
\hline Alter settings & Not allowed & Allowed (registered users) \\
\hline File format & Text files with .pos extension & Text files with .sum extension \\
\hline Mapping functions & Global mapping function (GMF) & Global mapping function (GMF) \\
\hline
\end{tabular}

\section{Results}

Computed ZTDs for the three processing approaches were matched against Day-of-year (DoY) and descriptive statistics were run to determine how the 3 results are related. Table 2 shows the results with a corresponding box plot in Figure 2 showing the spread and outliers. The results show the means, $\mu$, of the software agree to the second decimals, same with standard deviation, $\sigma$, but gLAB gave a wider range with some multiple outliers.

Table 2: Descriptive Statistics on computed ZTD

\begin{tabular}{r|lll} 
& APPS & CSRS & gLAB \\
\hline$\mu$ & 2.52328 & 2.52097 & 2.52616 \\
$\sigma$ & 0.03218 & 0.03424 & 0.03519 \\
$\varepsilon$ & 0.00095 & 0.00101 & 0.00104 \\
Range & 0.1438 & 0.2706 & 0.3815
\end{tabular}

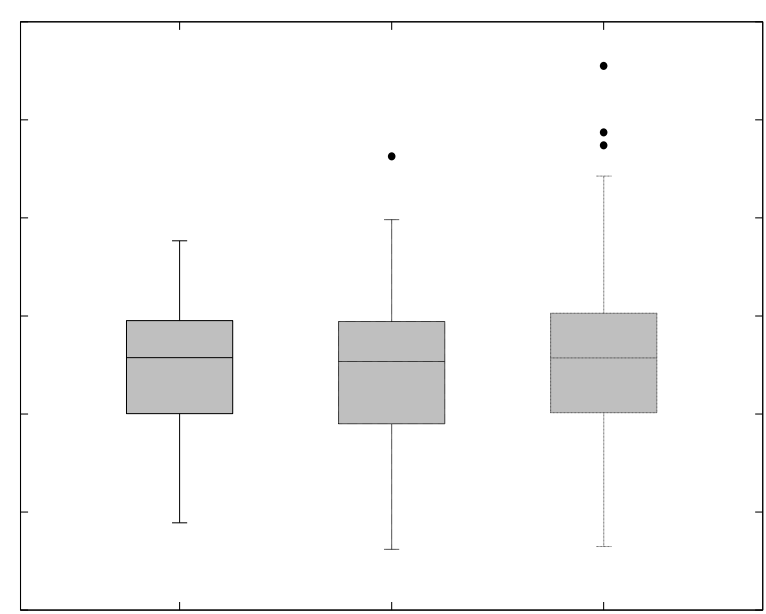

Figure 2: Box plot showing data distribution of computed ZTD from the 3 processing approaches

Further analyses were conducted to compute the correlation coefficients between gLAB ZTD values and ZTDs obtained from APPS and CSRS servers. The results were 0.8004 for APPS and 0.9165 for CSRS (Figure 3), these values clearly show that gLAB, APPS and CSRS are highly and positively correlated. The differences in values may be attributed to different tropospheric models, elevation masks set and surface meteorological values implemented in the various software. The statistics and resulting values indicate that gLAB compares favourably with CSRS-PPP than APPS which uses the GIPSY/OASIS processing engine. Precipitable Water were then retrieved from the ZTDs based on formulas defined in Section 2. 
A plot showing computed PW using ZTD from the three software against the data extracted from the reanalysis models are shown in Figure 4. Comparative analysis for the different methods used in deriving PW for the study area were done and the resulting correlation coefficients, $r$ matrix is given in Table 3. Precipitable Water (PW) quantities report by NCEP reanalysis were the highest for the reporting period, followed by ERA-Interim with JRA giving the least values. Values retrieved from the GPS signals gave the smallest ranges of $\approx 6 \mathrm{~mm}$ in PW over the study period whilst JRA recorded the highest range of $\approx 23 \mathrm{~mm}$. Comparing PW retrieved from GPS signals with the reanalysis models, APPS gave the highest correlation for all the three reanalysis models followed by CSRS and gLAB (refer Table 2). Even though all three PPP techniques showed positive correlations with all reanalysis models, $r$ values for ERA-Interim was the highest in each category. $r$ values for ERA-Interim with APPS, CSRS and gLAB are 0.8667, 0.7843 and 0.7261 respectively. Similar study by Motell et al. (2002) Advanced Very High Resolution Radiometer (AVHRR) split-window techniques and radiosondes over Hawaii resulted in $r$ of 0.66. Gutman et al. (2003) working at a site in North Central Oklahoma, compared rawinsonde with GPS water vapour retrievals and recorded correlation coefficient of 0.993. Other assignments have been carried out in the past (Mims et al. (2011); Bokoye et al. (2003); Yoshihara et al. (2000)) all aimed at comparing PW values retrieved from GPS, radiosonde, sun photometers, radiometers and other sensing approaches reported positive correlations.
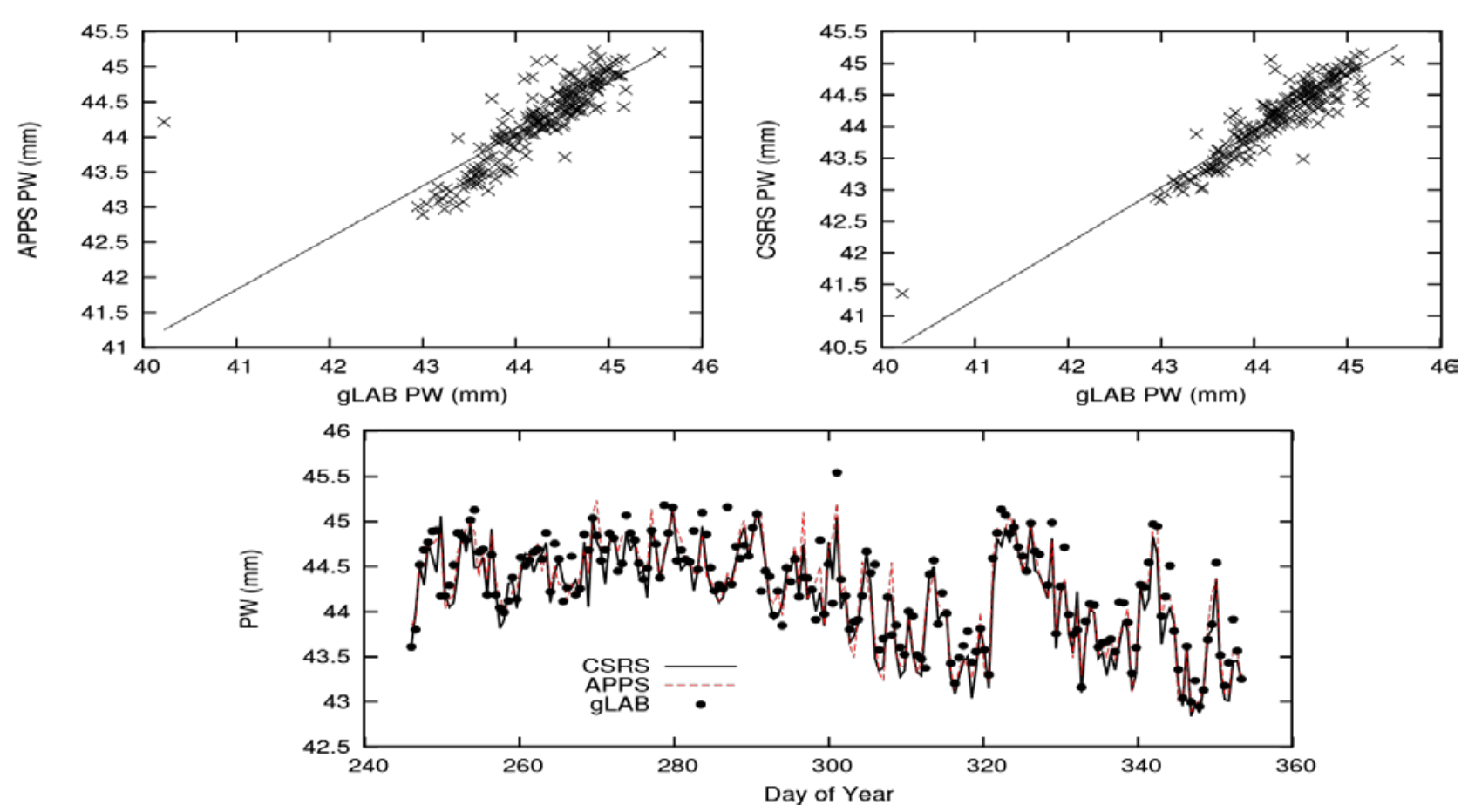

Figure 3: Correlation plot APPS and CSRS values against gLAB, and Retrieved PW from the various software against Day of the Year 
South African Journal of Geomatics, Vol. 6. No. 3, October 2017

Table 3: Matrix of Correlations for PW

\begin{tabular}{|llllll|} 
APPS & CSRS & gLAB & JRA & ERA & NCEP \\
\hline 1.0000 & 0.9079 & 0.8004 & 0.8203 & 0.8667 & 0.6352 \\
0.9079 & 1.0000 & 0.9165 & 0.7289 & 0.7843 & 0.5986 \\
0.8004 & 0.9165 & 1.0000 & 0.6690 & 0.7261 & 0.5454 \\
0.8203 & 0.7289 & 0.6690 & 1.0000 & 0.8368 & 0.6358 \\
0.8667 & 0.7843 & 0.7261 & 0.8368 & 1.0000 & 0.7149 \\
0.6352 & 0.5986 & 0.5454 & 0.6358 & 0.7149 & 1.0000 \\
\hline
\end{tabular}
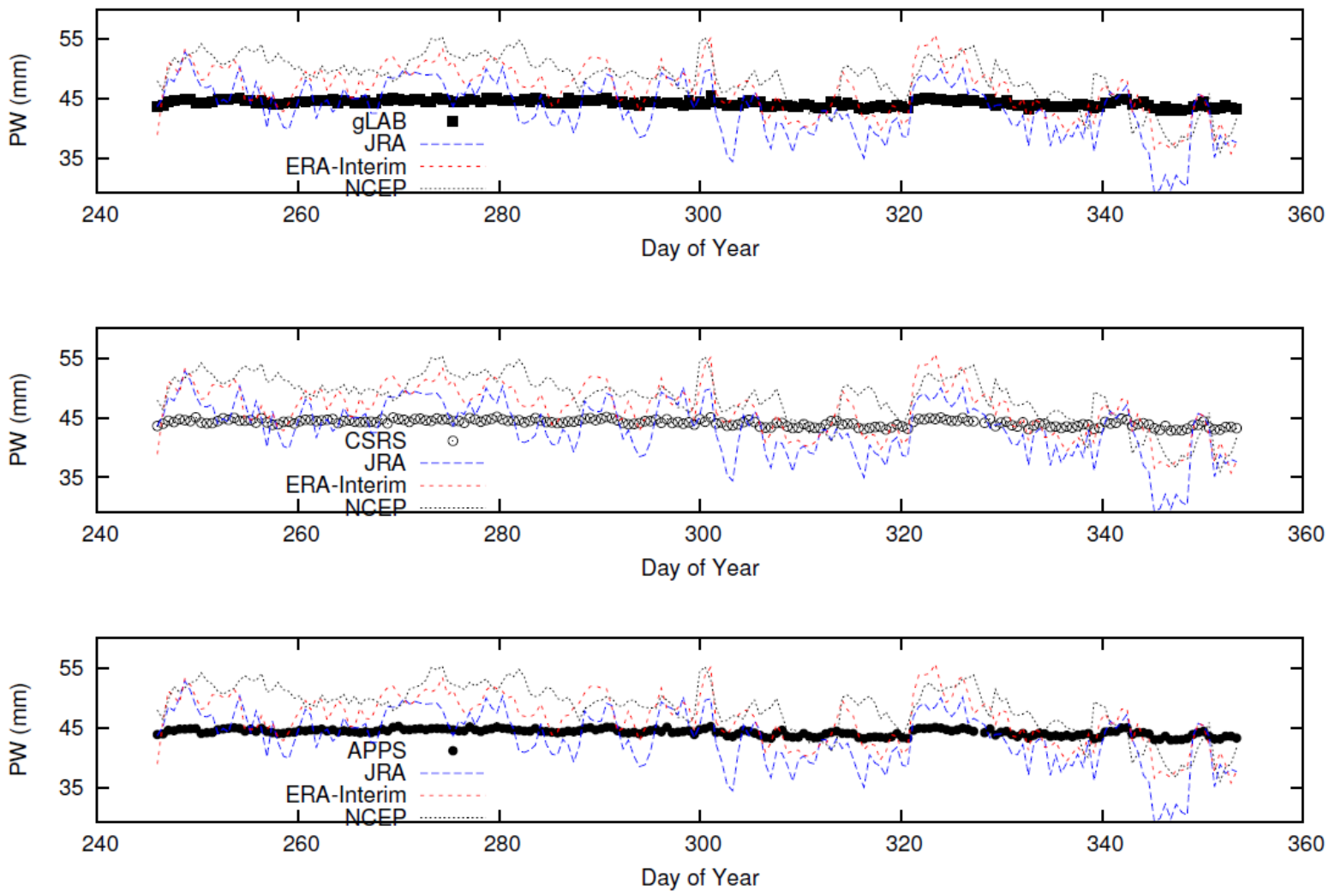

Figure 4: Plots showing Precipitable Water from Reanalysis models and computed from GPS signals against Day of Year

\section{Conclusions}

GNSS signals coupled with surface meteorological data can be utilized to derive tropospheric delays and PW with high accuracy. We have shown that when IGS precise products are applied, whichever PPP approach used in computing ZTD, the retrieved PW will compare favourably with other remote water vapour sensing devices. While GNSS-sensed PW is found to generally agree and positively correlates with Reanalysis models, the findings show that ERA-Interim is the best. However, these findings are not to rate one reanalysis over the other but to point that for atmospheric water vapour sampling over Kumasi, ERA-Interim samples better. Summing up, GNSS measurements can be logged as frequently at a rate of 1sec making the concept of GNSS meteorology much more advantageous in sampling temporal variability of atmospheric water vapour. 


\section{Acknowledgements}

Funds for this study were partly provided by DANIDA through Building Stronger Universities' Environment \& Climate Platform (www.bsuec.org).

\section{References}

Altamimi, Z., Collilieux, X., and M'etivier, L. (2011). ITRF2008: an improved solution of the international terrestrial reference frame. Journal of Geodesy, 85(8):457-473.

Andersson, E. (2014). Statement of guidance for global numerical weather prediction. https://www.wmo.int/pages/prog/www/OSY/SOG/SoG-Global-NWP.pdf. WMO’s Inter Programme Expert Team on the Observing System Design and Evolution.

APPS (2015). Automatic precise positioning service of the Global Differential GPS (GDGPS) system. http://apps.gdgps.net/. Jet Propulsion Laboratory, California Institute of Technology.

Askne, J. and Nordius, H. (1987). Estimation of tropospheric delay for microwaves from surface weather data. Radio Science, 22(3):379-386.

Bengtsson, L., Robinson, G., Anthes, R., Aonashi, K., Dodson, A., Elgered, G., Gendt, G., Gurney, R., Jietai, M., Mitchell, C., et al. (2003). The use of GPS measurements for water vapor determination. Bulletin of the American Meteorological Society, 84(9):1249-1258.

Bennitt, G. V. and Jupp, A. (2012). Operational assimilation of GPS zenith total delay observations into the met office numerical weather prediction models. Monthly Weather Review, 140(8):2706-2719.

Bevis, M., Businger, S., Chiswell, S., Herring, T. A., Anthes, R. A., Rocken, C., and Ware, R. H. (1994). GPS meteorology: Mapping zenith wet delays onto precipitable water. Journal of Applied Meteorology, 33(3):379-386.

Bevis, M., Businger, S., Herring, T., Rocken, C., Anthes, R., and Ware, R. (1992). GPS meteorology- remote sensing of atmospheric water vapor using the global positioning system. Journal of Geophysical Research, 97(D14):15787-15801.

Bokoye, A. I., Royer, A., O’Neill, N. T., Cliche, P., McArthur, L. J. B., Teillet, P. M., Fedosejevs, G., and Th'eriault, J.-M. (2003). Multisensor analysis of integrated atmospheric water vapor over Canada and Alaska. Journal of Geophysical Research: Atmospheres (1984-2012), 108(D15).

CSRS (2015). Canadian spatial reference system precise point positioning. http://webapp.geod.nrcan.gc.ca/geod/tools-outils/ppp.php. Natural Resources Canada.

Dattore, B. et al. (2015). NCEP climate forecast system version 2 (CFSv2). Computational and Information Systems Laboratory at the National Center for Atmospheric Research in Boulder, Colorado. http://rda.ucar.edu/datasets/ds094.0/ Accessed on May 2015.

Dee, D. P., Uppala, S. M., Simmons, A. J., Berrisford, P., Poli, P., Kobayashi, S., et al. (2011). The ERAInterim reanalysis: Configuration and performance of the data assimilation system. Quarterly Journal of the Royal Meteorological Society, 137(656):553-597.

Ebita, A., Kobayashi, S., Ota, Y., Moriya, M., Kumabe, R., Onogi, K., Harada, Y., Yasui, S., Miyaoka, K., Takahashi, K., et al. (2011). The Japanese 55-year reanalysis JRA-55: an interim report. Scientific Online Letters on the Atmosphere, 7:149-152.

Elgered, G., Davis, J. L., Herring, T. A., and Shapiro, I. I. (1991). Geodesy by radio interferometry: Water vapor radiometry for estimation of the wet delay. Journal of Geophysical Research: Solid Earth (19782012), 96(B4):6541-6555. 
England, M. N., R. A. Ferrare, S. H. Melfi, D. N. Whiteman, and T. A. Clark (1992), Atmospheric water vapor measurements: Comparison of microwave radiometry and lidar, J. Geophys. Res., 97(D1), 899-916, doi:10.1029/91JD02384.

Estey, L. H. and Meertens, C. M. (1999). TEQC: the multi-purpose toolkit for GPS/GLONASS data. GPS Solutions, 3(1):42-49.

Gendt, G.and Dick, G., Reigber, C. H., Tomassini, M., Liu, Y., and Ramatschi, M. (2003). Demonstration of NRT GPS water vapor monitoring for numerical weather prediction in Germany. Journal of Meteorological Soceity of Japan, 82(1B):360-370.

Gutman, S. I., Sahm, S. R., Stewart, J., Benjamin, S., Smith, T., and Schwartz, B. (2003). A new composite observing system strategy for ground-based GPS meteorology, paper presented at the 12th symposium on meteorological observations and instrumentation. Am. Meteorol. Soc., Boston, Mass.

Hernandez-Pajares, M., Juan, J. M., Sanz, J., Ramos-Bosch, P., Rovira-Garcia, A., Salazar, D., VenturaTraveset, J., L'opez-Echazarreta, C., and Hein, G. (2010). The ESA/UPC GNSS-lab tool (glab). In Proc. of the 5th ESA Workshop on Satellite Navigation Technologies (NAVITEC'2010), ESTEC, Noordwijk, The Netherlands.

IPCC, 2014, IPCC, 2014: Climate Change 2014: Synthesis Report. Team, C. W., Pachauri, R. K., \& Meyer, L. A. Eds. Contribution of Working Groups I. II and III to the Fifth Assessment Report of the intergovernmental panel on Climate Change. IPCC, Geneva, Switzerland, 151.

Johnsen, K.-P. and Kidder, S. (2002). Water vapor over Europe obtained from remote sensors and compared with a hydrostatic NWP model. Physics and Chemistry of the Earth, Parts A/B/C, 27(4):371-375.

Kistler, R., Collins, W., Saha, S., White, G., Woollen, J., Kalnay, E., Chelliah, M., Ebisuzaki, W., Kanamitsu, M., Kousky, V., et al. (2001). The NCEP-NCAR 50-year reanalysis: Monthly means CD-ROM and documentation. Bulletin of the American Meteorological society, 82(2):247-267.

Klobuchar, J. (1996). Ionospheric effects on GPS. Global Positioning System: Theory and applications., $1: 485-515$.

Kouba, J. and H'eroux, P. (2001). Precise point positioning using IGS orbit and clock products. GPS solutions, 5(2):12-28.

Lichten, S. M., Bar-Sever, Y. E., Bertiger, W. I., Heflin, M., Hurst, K., Muellerschoen, R. J., Wu, S. C., Yunck, T. P., and Zumberge, J. (2005). Gipsy-Oasis II: A high precision GPS data processing system and general satellite orbit analysis tool. Technology, pages 24-26.

Liou, Y.-A., Teng, Y.-T., Van Hove, T., and Liljegren, J. C. (2001). Comparison of precipitable water observations in the near tropics by GPS, microwave radiometer, and radiosondes. Journal of Applied Meteorology, 40(1):5-15.

Maghrabi, A., \& Al Dajani, H. M. (2013). Estimation of precipitable water vapour using vapour pressure and air temperature in an arid region in central Saudi Arabia. Journal of the Association of Arab Universities for Basic and Applied Sciences, 14(1), 1-8.

Mims, F. M., Chambers, L. H., and Brooks, D. R. (2011). Measuring total column water vapor by pointing an infrared thermometer at the sky. Bulletin of the American Meteorological Society, 92(10).

Mireault, Y., T'etreault, P., Lahaye, F., H'eroux, P., and Kouba, J. (2008). Online precise point positioning: A new, timely service from natural resources Canada. GPS World, September, pages 59-64.

Misra, P. and Enge, P. (2011). Global Positioning System: Signals, Measurements and Performance Revised 2nd Ed. Massachusetts: Ganga-Jamuna Press. 
Motell, C., Porter, J., Foster, J., Bevis, M., and Businger, S. (2002). Comparison of precipitable water over Hawaii using AVHRR-based split-window techniques, GPS and radiosondes. International Journal of Remote Sensing, 23(11):2335-2339.

Pachauri, R. K., Allen, M. R., Barros, V. R., Broome, J., Cramer, W., Christ, R., ... \& Dubash, N. K. (2014). Climate change 2014: synthesis report. Contribution of Working Groups I, II and III to the fifth assessment report of the Intergovernmental Panel on Climate Change (p. 151). IPCC.

Pérez-Ramírez, D., Navas-Guzmán, F., Lyamani, H., Fernández-Gálvez, J., Olmo, F. J., \& Alados-Arboledas, L. (2012). Retrievals of precipitable water vapor using star photometry: Assessment with Raman lidar and link to sun photometry. Journal of Geophysical Research: Atmospheres, 117(D5).

Pichelli, E., Ferretti, R., Cimini, D., Perissin, D., Montopoli, M., Marzano, F. S., and Pierdicca, N. (2010). Water vapour distribution at urban scale using high-resolution numerical weather model and spaceborne SAR interferometric data. Natural Hazards and Earth System Science, 10(1):121-132.

Pierdicca, N., Rocca, F., Basili, P., Bonafoni, S., Cimini, D., Ciotti, P., Ferretti, R., Foster, W., Marzano, F. S., Mattioli, V., et al. (2009). Atmospheric water-vapour effects on spaceborne interferometric SAR imaging: data synergy and comparison with ground-based measurements and meteorological model simulations at urban scale. In Antennas and Propagation, 2009. EuCAP 2009. 3rd European Conference on, pages 34433447. IEEE.

Pottiaux, E. (2010). Sounding the Earth's Atmospheric Water Vapour Using Signals Emitted by Global Navigation Satellite Systems. PhD thesis, Department of Physics, Earth and Life Institute, Catholic University of Louvain.

Rocken, C., Ware, R., Van Hove, T., Solheim, F., Alber, C., Johnson, J., Bevis, M., and Businger, S. (1993). Sensing atmospheric water vapor with the global positioning system. Geophysical Research Letters, 20(23):2631-2634.

Sahoo, S., Bosch-Lluis, X., Reising, S. C., and Vivekanandan, J. (2013). Spatial resolution and accuracy of retrievals of 2D and 3D water vapor fields from ground-based microwave radiometer networks. In Radio Science Meeting (USNC-URSI NRSM), 2013 US National Committee of URSI National. IEEE.

Schu“ler, T. (2006). GNSS meteorology on moving platforms. Advances and limitations in kinematic water wapor estimation. Inside GNSS, 1(3):56-60.

Schulzweida, U., Kornblueh, L., and Quast, R. (2009). Climate data operators (CDO), user guide, version 1.4.0. https://code.zmaw.de/projects/cdo.

Seidel, D. J. (2002). Water vapor: Distribution and trends. Encyclopedia of Global Environmental Change, John Wiley \& Sons, Ltd, Chichester.

Seidel, D. J., Berger, F. H., Immler, F., Sommer, M., V“omel, H., Diamond, H. J., Dykema, J., Goodrich, D., Murray, W., Peterson, T., et al. (2009). Reference upper-air observations for climate: Rationale, progress, and plans. Bulletin of the American Meteorological Society, 90(3):361-369.

Solheim, F. S. and Ware, R. H. (1997). Atmospheric water vapor sensing system using global positioning satellites. US Patent 5,675,081.

Solomon, S., Qin, D., Manning, M., Chen, Z., Marquis, M., Averyt, K. B., Tignor, M., and Miller, H. L. (2007). Climate change 2007: The physical science basis. contribution of working group $i$ to the fourth assessment report of the intergovernmental panel on climate change. Climate Change: the IPCC scientific assessment, page 996.

Subriana, J. S., Zornoza, J. M. J., and Hern'andez-Pajares, M. (2013). GNSS Data Processing, Vol 1: Fundamentals and Algorithms. ESA Communications, Noordwijk, the Netherlands. 
South African Journal of Geomatics, Vol. 6. No. 3, October 2017

T'etreault, P., Kouba, J., H'eroux, P., and Legree, P. (2005). CSRS-PPP: an internet service for GPS user access to the canadian spatial reference frame. Geomatica, 59(1):17-28.

Teunissen, H. (2003). Global climate observing system (GCOS). Global Atmosphere Watch, page 140.

USGS-Editors (2011). Greenhouse gases. Science Education Handout, http://education.usgs.gov/lessons/gases.pdf. Accessed on Feb 2013.

van der Marel, H., Brockmann, E., de Haan, S., Dousa, J., Johansson, J., Gendt, G., Kristiansen, O., Offiler, D., Pacione, R., Rius, A., et al. (2003). COST-716 near real-time demonstration project. Journal of the Meteorological Society of Japan.

Yoshihara, T., Tsuda, T., and Hirahara, K. (2000). High time resolution measurements of precipitable water vapor from propagation delay of GPS satellite signals. EARTH, PLANETS AND SPACE, 52(7):479-494.

Zebker, H. A., Rosen, P. A., and Hensley, S. (1997). Atmospheric effects in interferometric synthetic aperture radar surface deformation and topographic maps. Journal of Geophysical Research: Solid Earth (19782012), 102(B4):7547-7563. 